\title{
Immunological studies in retinitis pigmentosa associated with retinal vascular leakage
}

\author{
D. J. SPALTON, A. H. S. RAHI, AND A. C. BIRD \\ From Moorfields Eye Hospital and the Institute of Ophthalmology, London
}

SUMMARY Seventeen patients with retinitis pigmentosa and vascular leakage were studied for humoral immunological abnormalities. Apart from raised levels of IgM in 5 patients no other abnormalities were found.

Retinal vascular leakage in patients with retinitis pigmentosa (RP) is well recognised (Spalton et al., 1978; ffytche, 1972; Grizzerd et al., 1978), and we have recently studied a number of these patients (Spalton et al., 1978).

Increased vascular permeability was shown in patients with all genetic types of RP (Spalton et al., 1978) and has been shown in several other genetically determined conditions such as dominant macular oedema (Deutman et al., 1976), Goldman Favre syndrome (Fishman et al., 1976), and Batten's disease (Spalton et al., 1978).

Retinal arterial narrowing is a well recognised feature of RP. Work on rats with hereditary degeneration or iodoacetate visual cell destruction suggested that the consequent loss of retinal thickness exposed the retinal vessels to increased oxygen tension and subsequent vasoconstriction (Dantzker and Gerstein, 1969; Gerstein and Dantzker, 1969). This is followed by arterial and capillary closure and destruction of vascular endothelium (Ashton, 1977). These experiments may provide a homologue for genetically determined retinal degeneration in man, and a similar process could result in vascular leakage in RP. However, in our patients peripheral vascular leakage occurred mostly from major veins without detectable capillary closure, suggesting that this explanation is inadequate. Alternatively, oedema may be a non-immune response to toxic products liberated by degenerating retina or pigment epithelium. Finally, the oedema may be caused by inflammation. The patterns of leakage in RP are similar to those in aphakic macular oedema and posterior uveitis, in which inflammation is thought to be the basis of the oedema. Therefore, it was reasonable to seek evidence to support the concept

Address for reprints: Mr D. J. Spalton, FRCS, St. Thomas's Hospital, London SE1 7EH that an inflammatory response could cause retinal oedema in RP.

Retinal outer segments and pigment epithelium are known to be antigenic (Rahi, 1970; Wacker and Kalsow, 1974; Rahi et al., 1974; Meyers, 1974; Reich D'Almeira and Rahi, 1974), and an immune response to these antigens may cause an inflammatory reaction and retinal oedema in patients with genetically determined retinal degeneration. We have screened a group of 17 patients who had RP and retinal vascular leakage for humoral immunological disturbances that might account for the increased vascular permeability.

\section{Methods}

From a group of 17 patients with retinitis pigmentosa and retinal vascular leakage a single $10-\mathrm{ml}$ specimen of blood was withdrawn prior to fluorescein angiography. This group of patients formed part of a larger series in which the inheritance and distribution of vascular leakage had been studied and reported on (Spalton et al., 1978).

The serum was analysed for levels of $\mathrm{IgG}, \operatorname{IgA}$, and IgM by standard techniques of radial immunodiffusion using ICL plates. WHO standard sera provided reference curves.

The $\mathrm{C}_{3}$ fraction of complement was measured by the standard Mancini technique, and $\mathrm{C}_{3}$ breakdown products were sought by counter immunoelectrophoresis (Rocket technique) (Laurell, 1966).

Immunofluorescence tests were performed on composite-block frozen sections consisting of liver, kidney, stomach, diaphragm, and parotid from rat and the stomach of a mouse to detect antibodies to cell nuclei (and nucleoli), mitochondria, microsomes, smooth and skeletal muscle, and reticulin fibres. Frozen sections of rat eyes were used to detect 
antibodies to photoreceptors and other retinal structures by immunofluorescent methods.

Haemagglutination tests for thyroglobulin and thyroid microsomal antibodies were performed using commercial preparations. IgM rheumatoid factor was measured using the Rheumaton (Wellcome) technique.

\section{Results}

Of the 17 patients with RP the inheritance was autosomal dominant in 4 and $\mathrm{X}$-linked in $3 ; 2$ other patients had affected relatives, but there was not enough information to distinguish between dominant and $\mathrm{X}$-linked inheritance. Of the 8 patients with no family history 2 were children with severe disease and were likely to have inherited it in an autosomal recessive manner. One of the patients with no family history had uniocular retinitis pigmentosa. All patients apart from 1 had leakage of fluorescein in the posterior pole; 7 patients had peripheral leakage of dye (see Table 1).

Rheumatoid factor was present in 2 patients; antinuclear antibody in 5 (Fig. 1); smooth muscle antibody in 6 (Fig. 2); gastric parietal cell antibody in 5 (Fig. 3); 6 patients had 2 or more antibodies present. The prevalence of these antibodies is slightly higher (especially smooth muscle antibody) than in a normal population (see Table 2). No

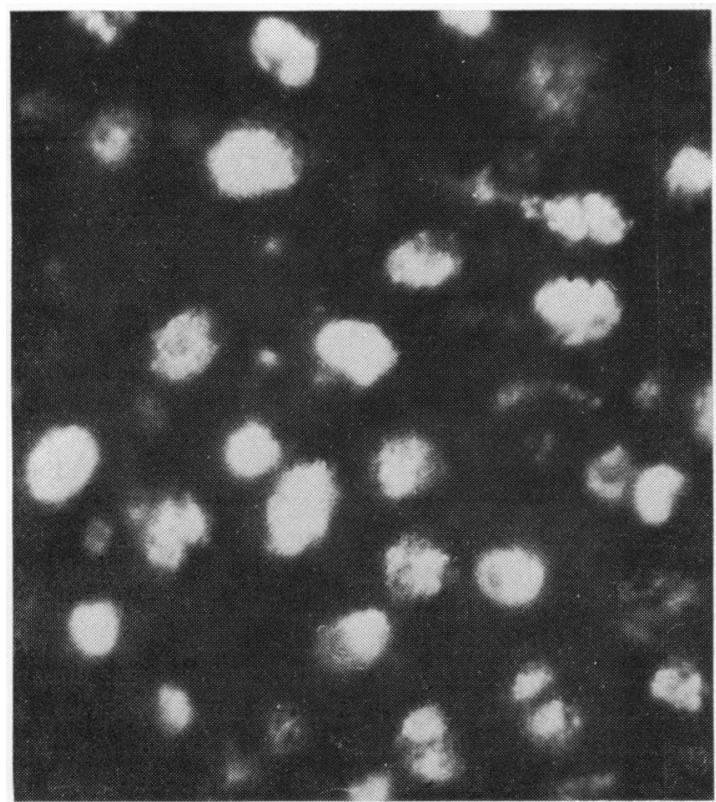

Fig. 1 Frozen section of rat liver showing nuclear fluorescence due to antinuclear antibody in patient's serum $\times 640$ patients had antithyroid, antimicrosomal, antimitochondrial, skeletal, or reticulin fibre antibody.

The levels of $\mathrm{C}_{3}$ were within the normal range, and there was no evidence of complement breakdown products in the blood of any of the patients.

Levels of IgG were within the normal range in all patients, and 1 patient had a low IgA level. Five patients had levels of IgM above the normal upper limit ( +2 SD).

\section{Discussion}

It has been previously reported that about a quarter of patients with RP have raised levels of IgM

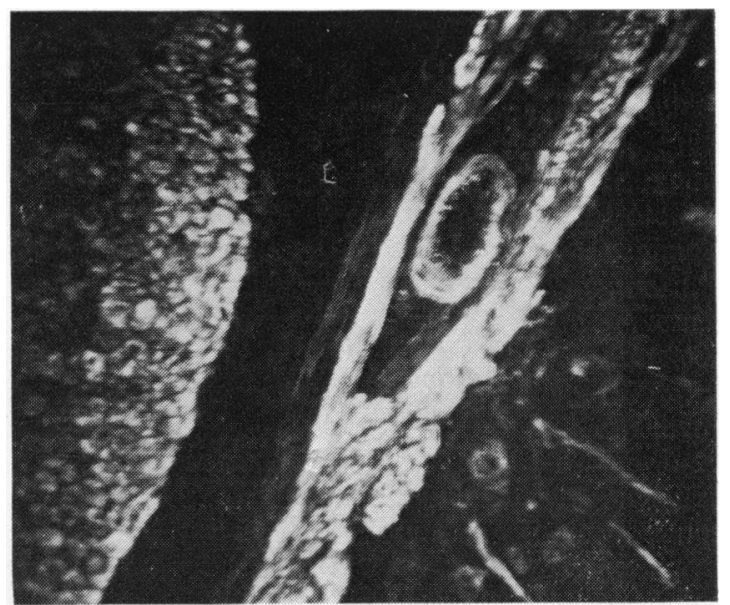

Fig. 2 Frozen section of rat stomach showing fuorescence of muscularis mucosa due to smooth muscle antibody in patient's serum $\times 450$

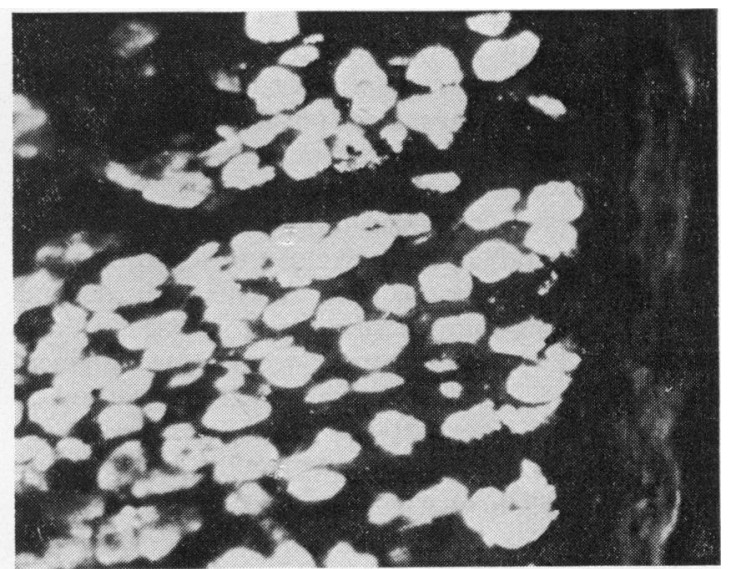

Fig. 3 Frozen section of mouse stomach showing bright fluorescence of gastric parietal cells due to specific antibody in patient's serum $\times \mathbf{4 5 0}$ 
Table 1 Analysis of patients

\begin{tabular}{|c|c|c|c|c|c|c|c|c|c|c|c|c|c|}
\hline \multirow{2}{*}{ Patient } & \multirow{2}{*}{ Age } & \multirow{2}{*}{ Sex } & \multirow{2}{*}{$\begin{array}{l}\text { Genetic type } \\
\text { of } R P\end{array}$} & \multirow{2}{*}{$\begin{array}{l}\text { Leakage } \\
\text { Central }\end{array}$} & \multirow[b]{2}{*}{ Peripheral } & \multicolumn{3}{|c|}{$\begin{array}{l}\text { Immunoglobulins } \\
\mathrm{IU} / \mathrm{ml}\end{array}$} & \multirow{2}{*}{$C_{3} m g \%$} & \multirow{2}{*}{$\begin{array}{l}\text { Titre of } \\
\text { rheumatoid } \\
\text { factor }\end{array}$} & \multirow{2}{*}{$\begin{array}{l}\text { Antinuclear } \\
\text { antibody } \\
I U / m l\end{array}$} & \multirow{2}{*}{$\begin{array}{l}\text { Gastric } \\
\text { parietal } \\
\text { cell } \\
\text { antibody }\end{array}$} & \multirow{2}{*}{$\begin{array}{l}\text { Smooth } \\
\text { nuscle } \\
\text { antibcdy }\end{array}$} \\
\hline & & & & & & $\operatorname{Ig} G$ & $\operatorname{Ig} A$ & $\operatorname{Ig} M$ & & & & & \\
\hline 1 & 26 & $\mathbf{F}$ & $\mathrm{AD}$ & + & - & 148 & 135 & 235 & 118 & - & - & - & $1: 10$ \\
\hline 2 & 21 & $\mathbf{F}$ & AD & + & + & 195 & 125 & 370 & 126 & - & - & $1: 40$ & $1: 10$ \\
\hline 3 & 43 & $\mathbf{M}$ & AD & + & + & 130 & 92 & 200 & 133 & $1: 10$ & 16 & - & - \\
\hline 4 & 49 & $\mathbf{M}$ & AD & + & - & 155 & 76 & 185 & 94 & - & - & - & - \\
\hline 5 & 22 & $\mathbf{M}$ & $\mathrm{XL}$ & $\div$ & - & 125 & 120 & 230 & 138 & - & - & - & $1: 40$ \\
\hline 6 & 23 & $\mathbf{M}$ & $\mathbf{X L}$ & + & - & 128 & 66 & 250 & 133 & - & - & - & $1: 40$ \\
\hline 7 & 23 & $\mathbf{M}$ & $\mathrm{XL}$ & + & - & 180 & 140 & 190 & 94 & - & - & - & - \\
\hline 8 & 10 & $\mathbf{F}$ & AR & + & + & 130 & 100 & 115 & 126 & - & 4 & $1: 40$ & - \\
\hline 9 & 6 & $\mathbf{M}$ & AR & + & + & 140 & 150 & 210 & 110 & - & - & - & - \\
\hline 10 & 25 & $\mathbf{F}$ & $\mathbf{S}$ & - & + & 105 & 37 & 280 & 111 & - & - & - & - \\
\hline 11 & 27 & $\mathbf{M}$ & $\mathbf{S}$ & \pm & - & 165 & 145 & 210 & 103 & $1: 10$ & - & - & - \\
\hline 12 & 29 & $F$ & $\mathbf{S}$ & + & + & 175 & 152 & 310 & 132 & - & -- & - & $1: 40$ \\
\hline 13 & 20 & $\mathbf{F}$ & $\mathbf{S}$ & + & - & 160 & 200 & 470 & 136 & - & 4 & $1: 10$ & - \\
\hline 14 & 21 & $\mathbf{F}$ & $\mathbf{S}$ & + & - & 205 & 141 & 508 & 160 & - & 4 & $1: 10$ & $1: 10$ \\
\hline 15 & 44 & $\mathbf{F}$ & $\mathrm{AD} / \mathrm{XL}$ & + & - & 165 & 110 & 440 & 185 & - & 4 & $1: 10$ & - \\
\hline 16 & 55 & $\mathbf{M}$ & $\mathrm{AD} / \mathrm{XL}$ & + & + & 190 & 300 & 290 & 130 & - & - & - & - \\
\hline 17 & 21 & $\mathbf{M}$ & $\mathbf{S}$ & + & - & 110 & 130 & 125 & & - & - & - & - \\
\hline
\end{tabular}

AD-Autosomal dominant. $\quad \mathrm{XL}-\mathrm{X}$-linked. $\mathrm{AR}-$ presumed autosomal recessive. $\mathrm{S}$-sporadic

Table 2 Normal values from 100 healthy adults (Rahi et al., 1976; Davies et al., 1976)

\begin{tabular}{llllll}
\hline IgG & mean & 121 & range & $70-282$ & $\mathrm{IU} / \mathrm{ml}$ \\
IgA & mean & 125 & range & $64-300$ & $\mathrm{IU} / \mathrm{ml}$ \\
$\mathrm{IgM}$ & mean & 151 & range & $68-300$ & $\mathrm{IU} / \mathrm{ml}$ \\
$\mathrm{C}_{3}$ & mean & 123 & range & $67-180$ & $\mathrm{mg} / 100 \mathrm{ml}$
\end{tabular}

Autoantibodies present in healthy adults (age 20-50 years)

Smooth muscle antibody present in $16 \%$ of healthy adults

Antinuclear antibody present in $15 \%$ of healthy adults

Rheumatoid factor present in $9 \%$ of healthy adults

Gastric parietal cell present in $3 \%$ of healthy adults

Antireticulin antibody present in $2 \%$ of healthy adults

(Rahi, 1973), and our series would appear to confirm this since the level of IgM was raised in 5 of 17 patients. The significance or explanation of this result is unknown. It does not relate to the degree of vascular leakage, as only 3 of the 7 patients with peripheral leakage had raised levels, and the patients with raised IgM did not show excessive leakage. It is of interest that 2 of the patients had proved dominant inheritance, and all 5 patients were female. Increased levels of IgM have also been found in patients with uveitis, especially if associated with vasculitis (Rahi et al., 1976).

Rheumatoid factor was present in only 2 patients, a smaller proportion than in some series (Fessel, 1962), and neither of these patients had raised levels of IgM. This discrepancy might be due to differences in technique. We have used a modified haemagglutination method which is known to be highly specific.

The proportions of patients who were found to have increased titres of antibodies, especially to smooth muscle but also to gastric parietal cells and nuclear antigens, appear to be higher than that found in a series of 100 normal adults (Rahi et al., 1976), but the numbers are small. It is unlikely that these antibodies would play an aetiological role, and they are probably formed in response to the release of antigenic proteins into the blood from damaged tissues. None of our patients was found to have antithyroid, antimitochondrial, antimicrosomal, skeletal muscle, or reticulin fibre antibody. Two twins were recently described with RP, endocrine problems, and high titres of thyroid antibodies (Nye and Howell Evans, 1977); it would appear 


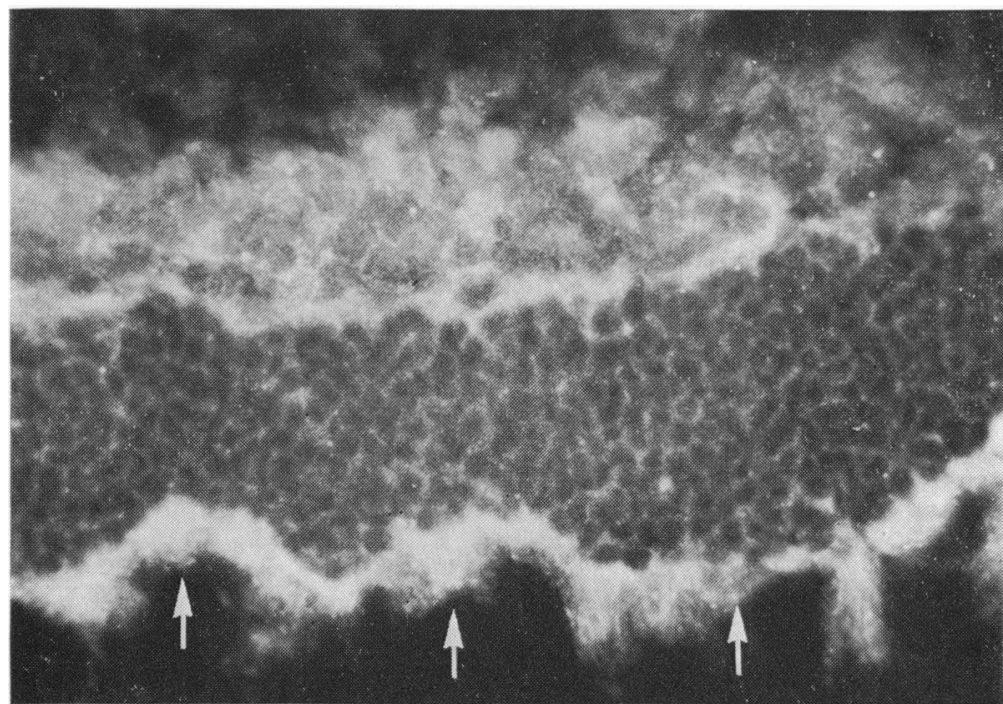

Fig. 4 Frozen section of rat retina treated with a $1: 5$ dilution of the patient's serum and fluorescein labelled antiimmunoglobulin $G$ showing fluorescence of the photoreceptors (arrows) $\times \mathbf{3 8 0}$

likely that the last would be more directly related to their endocrine problems than their RP.

We have attempted to show the presence of antibodies to rat photoreceptors in the serum of our patients by immunofluorescence, since it is known that rod outer segments are strongly antigenic and immunisation will induce uveoretinal lesions in guinea-pigs and rabbits (Wacker and Kalsow, 1974; Rahi et al., 1974; Meyers, 1974). All our patients showed positive immunofluorescence to photoreceptors at 1:5 dilution of serum (Fig. 4), but a large proportion of sera from healthy adults contain low titres of smooth muscle antibody and also show similar fluorescence. It was not possible, therefore, to distinguish whether the immunofluorescence was due to photoreceptor antibody or to smooth muscle antibodies cross-reacting with contractile organelles in the photoreceptors. The absorption of smooth muscle antibody from the sera is technically difficult owing to its diverse nature.

Immune complexes are known to be associated with vasculitis in many diseases such as systemic lupus erythematosus, rheumatoid arthritis, and erythema nodosum. All our patients had normal levels of $\mathrm{C}_{3}$. This is not surprising, as large amounts of complexes must be formed before the kinetics are disturbed enough to lower serum levels. It is more significant that we found no evidence of $\mathrm{C}_{3}$ breakdown products, a relatively more sensitive test for indicating the activation of $\mathrm{C}_{3}$. Nevertheless, our results do not exclude the presence of very small amounts of immune complexes. Indeed, if these were being formed and deposited locally, circulating complexes might be absent and their presence detected only by tissue studies.
Apart from raised levels of IgM in 5 patients we found no immunological disturbance to account for the vascular leakage, although it is not completely possible to exclude immune complex disease without tissue specimens, and cell mediated immunity has not been studied. It is possible that a toxic metabolite of degenerating retina or of pigment epithelium might cause vascular leakage by disturbing vascular endothelium, since this phenomenon is seen to be common to a number of genetically determined retinal dystrophies. Certainly our results do not suggest a consistent humoral immunological basis.

\section{References}

Ashton, N. (1977). Personal communication.

Dantzker, D. R., and Gerstein, D. D. (1969). Retinal vascular changes following toxic effects on visual cells and pigment epithelium. Archives of Ophthalmology, 81, 106-114.

Davies, P. D., Lobascher, D., Menon, J. A., Rahi A. H. S., and Ruben, M. (1976). Immunological studies in keratoconus. Transactions of the Ophthalmological Societies of the United Kingdom, 96, 173-178.

Deutman, A. F., Pinckers, A. J. L. G., and Aan de Kerk, A. L. (1976). Dominantly inherited cystoid macular edema. American Journal of Ophthalmology, 82, 540-548.

Fessel, W. J. (1962). Serum protein disturbance in retinitis pigmentosa. American Journal of Ophthalmology, 53, 640-642.

ffytche, T. J. (1972). Cystoid maculopathy in retinitis pigmentosa. Transactions of the Ophthalmological Societies of the United Kingdom, 92, 265-283.

Fishman, G. A., Jampol, L. M., and Goldberg, M. F. (1976). Diagnostic features of the Favre-Goldman syndrome. British Journal of Ophthalmology, 60, 345-353.

Gerstein, D. D., and Dantzker, D. R. (1969). Retinal vascular changes in hereditary visual cell degeneration. Archives of Ophthalmology, 81, 99-106.

Grizzerd, W. S., Deutman, A. F., and Pinckers, A. J. L. G. (1978). Retinal dystrophies associated with peripheral 
retinal vasculopathy. British Journal of Ophthalmology, 62, 188-194.

Laurell, C. B. (1966). Quantitative estimations of proteins by electrophoresis in agarose gell containing antibodies. Analytical Biochemistry, 15, 42-52.

Meyers, R. L. (1974). Experimental allergic uveitis: induction by retinal rod outer segments and pigment epithelium. Proceedings of the 1st symposium on immunology and immunopathology of the eye. Modern problems in Ophthalmology, 16, 41-50.

Nye, F. J., and Howell Evans, W. (1977). Retinitis pigmentosa and autoimmune endocrine abnormalities in identical twins. British Medical Journal, 1, 616-617.

Rahi, A. H. S. (1970). Antigenic specificity of photoreceptor cells. British Journal of Ophthalmology, 54, 441-444.

Rahi, A. H. S. (1973). Autoimmunity and the retina. British Journal of Ophthalmology, 51, 904-909.

Rahi, A. H. S., Holborrow, E. J., Perkins, E. S., Gungen, Y. Y., and Dinning, W. J. (1976). Immunological studies in uveitis. Transactions of the Ophthalmological Societies of the United Kingdom, 96, 113-122.

Rahi, A. H. S., Lucas, D. R., and Waghe, M. (1974). Experimental immune retinitis: induction by isolated photoreceptors. Proceedings of the 1st symposium on immunology and immunopathology of the eye. Modern Problems in Ophthalmology, 16, 30-40.

Reich D'Almeira, F., and Rahi, A. H. S. (1974). Antigenic specificity of retinal pigment epithelium and non-immunological involvement in retinal dystrophy. Nature, 252, 307-308.

Spalton, D. J., Bird, A. C., and Cleary, P. E. (1978). Retinitis pigmentosa and retinal oedema. British Journal of Ophthalmology, 62, 174-182.

Wacker, W. B., and Kalsow, C. M. (1974). The role of uveal and retinal antigens in experimental ocular pathology. Proceedings of the 1st symposium on immunology and immunopathology of the eye. Modern Problems in Ophthalmology, 16, 12-20. 